\title{
Systematic review of natural and miscellaneous agents, for the management of oral mucositis in cancer patients and clinical practice guidelines - part 2: honey, herbal compounds, saliva stimulants, probiotics, and miscellaneous agents
}

\author{
Noam Yarom ${ }^{1,2}$ (D) $\cdot$ Allan Hovan ${ }^{3} \cdot$ Paolo Bossi $^{4} \cdot$ Anura Ariyawardana $^{5,6} \cdot$ Siri Beier Jensen ${ }^{7} \cdot$ Margherita Gobbo $^{8}$. \\ Hanan Saca-Hazboun ${ }^{9} \cdot$ Abhishek Kandwal $^{10}$ - Alessandra Majorana ${ }^{11}$ • Giulia Ottaviani ${ }^{8}$. Monica Pentenero ${ }^{12}$.

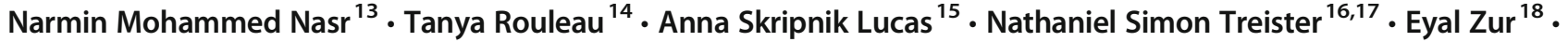 \\ Vinisha Ranna ${ }^{19}$ - Anusha Vaddi ${ }^{20,21}$ - Andrei Barasch ${ }^{22} \cdot$ Rajesh V Lalla $^{21} \cdot$ Karis Kin Fong Cheng $^{23} \cdot$ Sharon Elad $^{20} \cdot$ On $^{2}$ \\ behalf of the Mucositis Study Group of the Multinational Association of Supportive Care in Cancer / International \\ Society of Oral Oncology (MASCC/ISOO)
}

Received: 4 October 2019 / Accepted: 18 December 2019

(C) Springer-Verlag GmbH Germany, part of Springer Nature 2020

\begin{abstract}
Objective To update the clinical practice guidelines for the management of oral mucositis (OM) that were developed by the Multinational Association of Supportive Care in Cancer/International Society of Oral Oncology (MASCC/ISOO). This part focuses on honey, herbal compounds, saliva stimulants, probiotics, and miscellaneous agents.

Methods A systematic review was conducted by the Mucositis Study Group of MASCC/ISOO. The body of evidence for each intervention, in each clinical setting, was assigned an evidence level. The findings were added to the database used to develop the 2014 MASCC/ISOO clinical practice guidelines. Based on the evidence level, one of the following guidelines were determined: Recommendation, Suggestion, No Guideline Possible.

Results A total of 78 papers were identified within the scope of this section, of which 49 were included in this review and merged with nine publications that were reported in the previous guidelines update. A new Suggestion was made for honey (combined topical and systemic delivery) for the prevention of OM in head and neck cancer patients receiving radiotherapy with or without chemotherapy. A new Suggestion clarified that chewing gum is not effective for the prevention of OM in pediatric patients with hematological or solid cancer treated with chemotherapy. No guideline was possible for other interventions.

Conclusions Numerous natural products and herbal remedies were studied for the management of OM. Of the agents reviewed in this systematic review, a guideline in favor was made for honey (combined topical and systemic), while a guideline against was made for chewing gum. Additional research is warranted to clarify the potential of other interventions.
\end{abstract}

Keywords Oral mucositis $\cdot$ Cancer $\cdot$ Management $\cdot$ Natural $\cdot$ Traditional $\cdot$ Complementary $\cdot$ Herbal

\section{Introduction}

Among all cancer treatment toxicities, oral mucositis (OM) is a common and significant complication. It is frequently observed in head and neck (H\&N) cancer patients undergoing

Noam Yarom

Noam.yarom@sheba.health.gov.il

Extended author information available on the last page of the article radiotherapy (RT) with or without concomitant chemotherapy (CT) and in patients undergoing hematopoietic stem cell transplantation (HSCT) [1]. Clinically, it manifests as erythema and/or ulcerations involving the non-keratinized oral mucosa, causing severe pain and/or dysphagia, and may result in treatment breaks and prolonged hospitalization.

"In the search for OM prevention, treatment, or palliation, a broad variety of natural remedies have been suggested. For many generations, natural remedies have been used for the management of oral ulcerations in various cultures across the world. Unlike synthetic drugs, natural remedies are 
generally perceived to have fewer side effects and are therefore attractive as potential therapies. Patient-based access to these products in resource-restricted geographic regions may be an additional advantage as well.

The Mucositis Study Group (MSG) of the Multinational Association of Supportive Care in Cancer/ International Society of Oral Oncology (MASCC/ISOO) has published clinical practice guidelines for the management of OM [2-4]. In the 2014 guidelines update, the Natural and Miscellaneous section concluded the systematic review with two guidelines regarding honey, herbal compounds, saliva stimulants/inhibitors, probiotics, and miscellaneous agents: (1) a suggestion against the use of systemic pilocarpine administered orally for the prevention of OM associated with RT for H\&N cancer and in patients receiving high-dose chemotherapy, with or without total body irradiation, prior to HSCT; (2) a suggestion against the use of systemic pentoxifylline administered orally for the prevention of $\mathrm{OM}$ in patients undergoing HSCT. No guideline was possible for any other agents $[5,6]$. The aim of this systematic review was to review newly reported evidence for the efficacy of natural and miscellaneous agents for the prevention and/or treatment of $\mathrm{OM}$ and update the clinical practice guidelines.

In the first part of this systematic review, we focused on the efficacy of vitamins, minerals, and nutritional supplements for the management of OM [7]. This paper includes studies on honey, herbal compounds, saliva stimulants/inhibitors, probiotics, and miscellaneous agents.

\section{Methods}

The methods are described in detail in Ranna et al. [8] Briefly, a literature search for relevant papers indexed in the literature from January 1, 2011 to June 30, 2016 was conducted using PubMed/Web of Science/EMBASE, with papers selected for review based on defined inclusion and exclusion criteria.

Papers were reviewed by two independent reviewers and data were extracted using a standard electronic form. Studies were scored for their level of evidence (LoE) based on Somerfield criteria [9] and flaws were listed according to Hadorn criteria [10]. A well-designed study was defined as a study with no major flaws per the Hadorn criteria.

Findings from the reviewed studies were integrated into guidelines based on the overall level of evidence for each intervention. Guidelines were classified into 3 types: Recommendation, Suggestion, and No Guideline Possible.

Guidelines were separated based on (1) the aim of the intervention (prevention or treatment of mucositis); (2) the treatment modality (RT, CT, RT-CT, or high-dose conditioning therapy for HSCT); and (3) the route of administration of the intervention.

The list of intervention keywords used for the literature search of this section are detailed in the Methods paper [8].

\section{Results}

A total of 2653 papers were identified in the literature search: 1863 from PubMed and 790 from Web of Science. After careful assessment of the abstracts, 2563 articles were excluded due to repetition across databases, non-clinical studies, metaanalyses and reviews. Three additional papers were transferred from other sections of the guidelines update leading to a total of ninety-three articles. After review of the full papers, 6 were moved to other sections, and 9 were excluded based on inclusion/exclusion criteria. A total of 78 papers were included in this section. Of them 49 were included in this paper (part 2) (Fig. 1), while 29 papers were included in part 1 [7]. These 49 publications describe 26 various interventions that fall within the scope of honey, herbal compounds, saliva stimulants/inhibitors, probiotics, and miscellaneous agents. These papers were merged with 9 publications that were reviewed in the previous guidelines update.

\section{Honey}

Honey has been reported to be effective in promoting wound healing when applied as a dressing [11]. The wound healing effect is considered to be primarily mediated by the low-level hydrogen peroxide generation. Interestingly, compared with diluted honey, full-strength honey has a lower glucose oxidase activity, and thus lower level of hydrogen peroxide generation [12]. There are also non-hydrogen peroxide phytochemical mechanisms which appear to be involved in wound healing. In addition, honey has anti-microbial properties which may be beneficial to prevent secondary infection [13].

\section{Honey (topical) - H\&N - RT or RT-CT - prevention}

\section{Guideline: No guideline possible (LoE II)}

Overall, in the $\mathrm{H} \& \mathrm{~N}$ cancer patient population, there were 4 RCTs for topical honey [Table 1] [14-17], Two of these RCTs demonstrated that honey was effective in preventing OM associated with RT or RT-CT [16,17]; however, these RCTs had a small sample size. Therefore, No Guidelines Possible. Interestingly, the two RCTs that reported honey is ineffective in preventing radiation-association OM were using Manuka honey. 


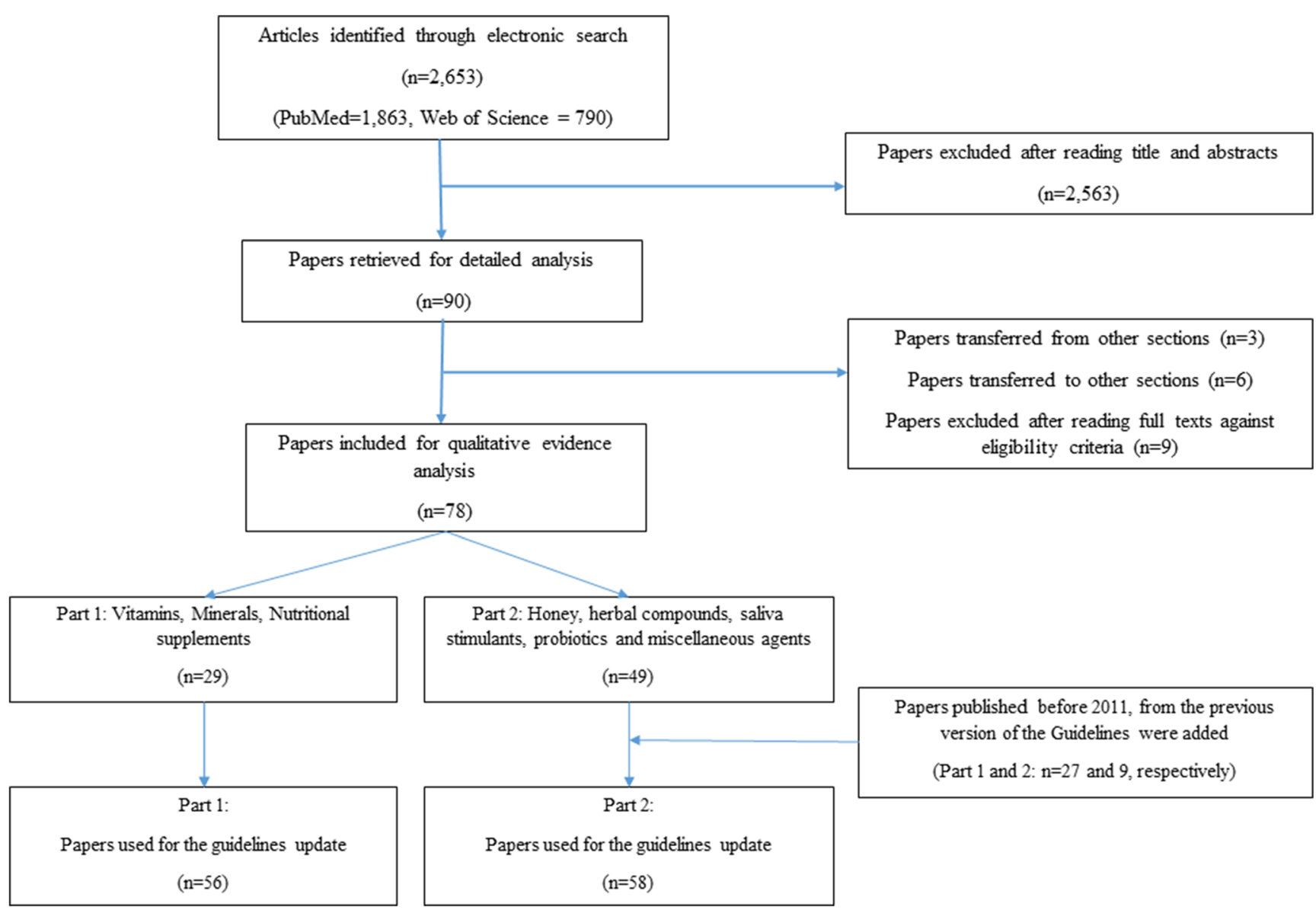

Fig. 1 Article flow chart

\section{Honey (combined topical-systemic) - H\&N - RT or RT-CT - prevention}

\section{Guideline: Suggestion (LoE III)}

Honey (combined topical application and systemic administration) is suggested for the prevention of OM in H\&N cancer patients treated with either RT or RT-CT.

There is consistent evidence that topical application combined with systemic administration of honey is beneficial in preventing $\mathrm{OM}$ in $\mathrm{H} \& \mathrm{~N}$ cancer patients treated with either $\mathrm{RT}$ or RT-CT [Table 1] [18-23]. Since some of these RCTs had a mixed patient population (RT and RT-CT), small sample size, and different sources for the honey, only a Suggestion can be made for the present guideline update.

Likewise, a single study had equivocal results as statistical significance was not reported [20]. Of note, there was an additional RCT comparing a combined protocol of honey, benzydamine, and nystatin with a control group that received benzydamine and nystatin only [24]. This latter RCT did not contribute to our analysis because the patient population was not clearly defined.
Two RCTs compared honey with another active agent and are considered comparator studies [25,26]. One RCT compared topical honey with topical lidocaine and found honey to be superior in reducing the OM severity in patients with $H \& N$ cancer [25]. In another RCT, honey was applied to prevent OM in an unspecified group of cancer patients treated with CT [26]. This study included 3 arms comparing honey with a mix of honey and caffeine, and with steroids ( $8 \mathrm{mg}$ betamethasone) [26], and found that the combined honey and caffeine had the greatest reduction in OM severity.

The source of the honey differed between these studies: "natural" honey [16,19], royal jelly [17,24], honey extracted mainly from the tea plant, Camellia sinensis [18], honey extracted from Thymus and Astragale in the Alborz mountains [21], honey extracted from the western Ghats forests [25], honey extracted from the clover plant Trifolium alexandrenum [22], or unspecified [20,23].

No data were reported regarding dental caries in the studies about honey-based protocols for the prevention of OM. 


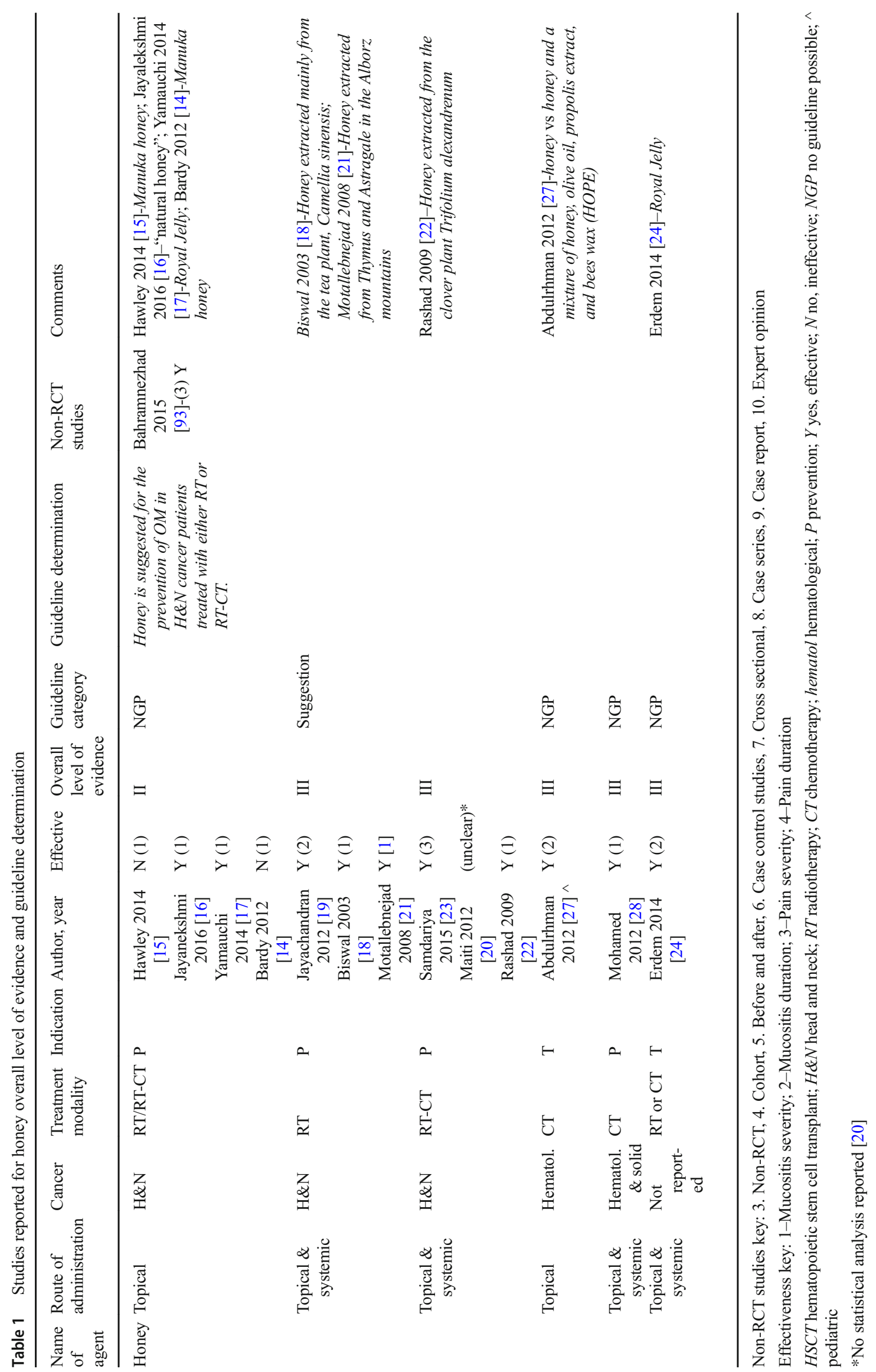


Honey (topical) - hematologic cancer - CT - treatment

Guideline: No guideline possible (LoE III)

This systematic review found a single RCT on honey as a treatment for $\mathrm{OM}$ among pediatric patients with hematologic malignancies treated with CT [27]. This study demonstrated that topical honey was effective in reducing the duration of OM but not its severity. Since there is a single RCT in this clinical setting, the guideline category is No Guideline Possible.

\section{Honey (topical) - hematologic or solid cancer - CT - prevention}

\section{Guideline: No guideline possible (LoE III)}

A RCT reported on honey for the prevention of $\mathrm{OM}$ in a mixed patient population of hematologic malignancies and solid cancers treated with CT [28]. This RCT reported that honey was effective to reduce OM severity. Considering the limited evidence, as well as the lack of placebo and blinding in this study, no guideline is possible.

\section{Propolis}

Propolis is a natural wax-like resinous substance collected by honey bees from the tree buds or other botanical sources such as poplar, willow, birch, elm, alder, beech, conifer, and horse-chestnut trees [29]. Propolis is used by Western and European honeybees as a building material in the hive [29]. The chemical composition of propolis varies and depends on the geographical area, time of collection, seasonality, illumination, altitude, and food availability during propolis [29].

Propolis has been used throughout history as a natural medicine [30]. Its antibacterial, antiseptic, anti-inflammatory, anti-fungal, anesthetic, and healing properties have been reported [30].

\section{Propolis (topical) - hematologic or solid cance - CT - treatment}

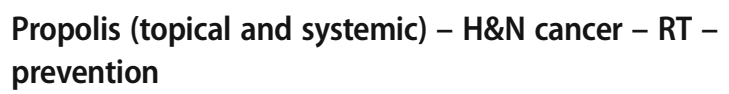

Each of the above categories had a single, small RCT [31-33] and an additional cohort study was reported for one of these categories (Table 2) [34]. This evidence was insufficient to determine a guideline for any of these categories.

\section{Traumeel}

Traumeel is a homeopathic intervention used to treat a variety of conditions related to inflammation. It contains several medicinal plants and minerals in very low concentrations: Arnica montana, Calendula officinalis, Atropa belladonna, Aconitum napellus, Bellis perennis, Hypericum perforatum, Echinacea angustifolia, Echinacea purpurea, Symphytum officinale, Matricaria chamomilla, Achillea millefolium, Mercurius solubilis hahnemanni [35].

Table 2 Studies reported for propolis, overall level of evidence, and guideline determination

\begin{tabular}{|c|c|c|c|c|c|c|c|c|c|}
\hline $\begin{array}{l}\text { Name of } \\
\text { agent }\end{array}$ & $\begin{array}{l}\text { Route of } \\
\text { administration }\end{array}$ & Cancer & $\begin{array}{l}\text { Treatment } \\
\text { modality }\end{array}$ & Indication & Author, year & Effective & $\begin{array}{l}\text { Overall level of } \\
\text { evidence }\end{array}$ & $\begin{array}{l}\text { Guideline } \\
\text { category }\end{array}$ & $\begin{array}{l}\text { Non-RCT } \\
\text { studies }\end{array}$ \\
\hline \multirow[t]{3}{*}{ Propolis } & Topical & $\begin{array}{l}\text { hematol. } \\
\text { \& solid }\end{array}$ & $\mathrm{CT}$ & $\mathrm{T}$ & $\begin{array}{l}\text { Tomazevic } 2013 \\
\text { [33] }\end{array}$ & $\mathrm{N}(1)$ & III & NGP & \multirow{3}{*}{$\begin{array}{c}\text { Noronha } 2014 \\
\text { [34]-(4) Y }\end{array}$} \\
\hline & $\begin{array}{l}\text { Topical \& } \\
\quad \text { systemic }\end{array}$ & $\mathrm{H} \& \mathrm{~N}$ & $\mathrm{RT}$ & $\mathrm{P}$ & $\begin{array}{l}\text { Javadzadeh Bolouri } \\
2015 \text { [32] }\end{array}$ & $\mathrm{Y}(1)$ & III & NGP & \\
\hline & Topical & $\mathrm{H} \& \mathrm{~N}$ & $\mathrm{CT}$ & $\mathrm{T}$ & $\begin{array}{l}\text { Akhavan-Karbassi } \\
2016 \text { [31] }\end{array}$ & Y (1) & III & NGP & \\
\hline
\end{tabular}

Non-RCT studies key: 3. Non-RCT, 4. Cohort, 5. Before and after, 6. Case control studies, 7. Cross sectional, 8. Case series, 9. Case report, 10. Expert opinion

Effectiveness key: 1-Mucositis severity; 2-Mucositis duration; 3-Pain severity; 4-Pain duration

$H S C T$ hematopoietic stem cell transplant; $H \& N$ head and neck; $R T$ radiotherapy; $C T$ chemotherapy; hematol hematological; $P$ prevention; $Y$ yes, effective; $N$ no, ineffective; $N G P$ no guideline possible; ${ }^{\wedge}$ pediatric 
Table 3 Studies reported for traumeel, overall level of evidence, and guideline determination

\begin{tabular}{|c|c|c|c|c|c|c|c|c|c|}
\hline $\begin{array}{l}\text { Name of } \\
\text { agent }\end{array}$ & $\begin{array}{l}\text { Route of } \\
\text { administration }\end{array}$ & Cancer & $\begin{array}{l}\text { Treatment } \\
\text { modality }\end{array}$ & Indication & Author, year & Effective & $\begin{array}{l}\text { Overall level of } \\
\text { evidence }\end{array}$ & $\begin{array}{l}\text { Guideline } \\
\text { category }\end{array}$ & Non-RCT studies \\
\hline \multirow[t]{3}{*}{ Traumeel } & \multirow[t]{2}{*}{$\begin{array}{l}\text { Topical \& } \\
\text { systemic }\end{array}$} & \multirow[t]{2}{*}{ hematol. } & \multirow[t]{2}{*}{$\mathrm{HSCT}^{\wedge}$} & \multirow[t]{2}{*}{$\mathrm{P}$} & $\begin{array}{l}\text { Oberbaum } \\
2001[36]^{\wedge}\end{array}$ & $\mathrm{Y}(1,2)$ & \multirow[t]{2}{*}{ II } & \multirow[t]{2}{*}{ NGP } & \\
\hline & & & & & $\begin{array}{c}\text { Sencer } 2012 \\
{[35]^{\wedge}}\end{array}$ & $\mathrm{N}(1)$ & & & \\
\hline & $\begin{array}{l}\text { Topical \& } \\
\text { systemic }\end{array}$ & $\mathrm{H} \& \mathrm{~N}$ & RT or RT-CT & $\mathrm{P}$ & & & III & NGP & $\begin{array}{c}\text { Steinmann } 2012 \\
\text { [37]-(3) N }\end{array}$ \\
\hline
\end{tabular}

Non-RCT studies key: 3. Non-RCT, 4. Cohort, 5. Before and after, 6. Case control studies, 7. Cross sectional, 8. Case series, 9. Case report, 10. Expert opinion

Effectiveness key: 1-Mucositis severity; 2-Mucositis duration; 3-Pain severity; 4-Pain duration

$H S C T$ hematopoietic stem cell transplant; $H \& N$ head and neck; $R T$ radiotherapy; $C T$ chemotherapy; hematol hematological; $P$ prevention; $Y$ yes, effective; $N$ no, ineffective; $N G P$ no guideline possible; $`$ pediatric

\section{Traumeel (topical and systemic) - hematologic cancer (pediatric) - HSCT - prevention}

\section{Traumeel (topical and systemic) - H\&N cancer - RT or RT-CT - prevention}

\section{Guideline: No guideline possible (LoE II and III, respectively)}

Two RCTs assessed traumeel as a preventive therapy for OM in HSCT pediatric patients [Table 3] [35,36]. Both studies instructed the patients to swish and swallow. These studies presented conflicting evidence, therefore no guideline is possible.

Another comparative study was performed in $\mathrm{H} \& \mathrm{~N}$ cancer patients treated with either RT or RT-CT [37]. This study reported that traumeel was not effective to prevent OM. Due to the limited evidence, no guideline is possible in this setting either.

\section{Saliva stimulation}

Saliva contains mucosal protective compounds that are vital for the oral health [38]. Among these salivary proteins are growth factors such as epidermal growth factor (EGF) and fibroblast growth factor (FGF) that promote wound healing and tissue repair. Animal models have shown delayed oral mucosal wound healing when salivary glands were mechanically obstructed, with the connective tissue being much more sensitive to lack of saliva than the epithelium [39]. Therefore, it has been suggested that any decrease in salivary flow may predispose the oral cavity to cytotoxic damage, whereas increasing salivary flow may support mucosal integrity and healing.

Chewing gum is a simple and inexpensive method to increase salivary production by up to 10 -fold [40]. Therefore, it is postulated that chewing a gum may be beneficial in the management of OM. Other modalities that increases the oral cavity moistening, such as electrostimulation of the salivary glands or production of an artificial humid climate, may work in a similar way.

\section{Chewing gum - hematologic/solid cancer (pediatric) - CT - prevention}

\section{Guideline: Suggestion (against) (LoE III)}

Chewing gum is not suggested for the prevention of OM in pediatric patients with hematological or solid cancer treated with CT.

This review identified 2 large RCTs assessing the potential of chewing gum for the prevention of $\mathrm{OM}$ in a mixed patient population of hematologic cancers and solid tumors [Table 4] $[41,42]$. Both studies were in pediatric patients and reported no difference between the treatment and control groups in regard to the reduction of OM severity. In one RCT, the chewing gum was compared with oral care alone [42] and in the second RCT, a combination of chewing gum and "magic mouthwash" was compared with "magic mouthwash" alone [41]. Considering the consistent evidence from 2 RCTs, a Suggestion against chewing gum was made.

\section{Artificial moistening - Hematologic cancer - HSCT - prevention}

\section{Artificial humidification - H\&N cancer - RT or RT-CT - prevention}

\section{Guideline: No guideline possible (LoE III)}

A single RCT was found for chewing gum in patients undergoing HSCT and reported that it was not effective in 
Table 4 Studies reported for saliva stimulants, overall level of evidence, and guideline determination

\begin{tabular}{|c|c|c|c|c|c|c|c|c|c|}
\hline Name of agent & $\begin{array}{l}\text { Route of } \\
\text { administration }\end{array}$ & Cancer & $\begin{array}{l}\text { Treatment } \\
\text { modality }\end{array}$ & Indication & $\begin{array}{l}\text { Author, } \\
\text { year }\end{array}$ & Effective & $\begin{array}{l}\text { Overall } \\
\text { level of } \\
\text { evidence }\end{array}$ & $\begin{array}{l}\text { Guideline } \\
\text { category }\end{array}$ & Guideline determination \\
\hline \multirow[t]{2}{*}{ Chewing gum } & Topical & $\underset{\wedge}{\text { Hematol./solid }}$ & $\mathrm{CT}$ & $\mathrm{P}$ & $\begin{array}{c}\text { Eghbali } \\
2016 \\
{[41]}\end{array}$ & $\mathrm{N}(1)$ & III & Suggestion & \multirow{5}{*}{$\begin{array}{l}\text { Chewing gum is not } \\
\text { suggested for the } \\
\text { prevention of OM in } \\
\text { pediatric patients with } \\
\text { hematological or solid } \\
\text { cancer treated with CT }\end{array}$} \\
\hline & Topical & $\underset{\wedge}{\text { Hematol./solid }}$ & $\mathrm{CT}$ & $\mathrm{P}$ & $\begin{array}{c}\text { Gandemer } \\
2007 \\
{[42]}\end{array}$ & $\mathrm{N}(1)$ & III & & \\
\hline $\begin{array}{l}\text { Chewing/electric } \\
\text { stimulation } \\
\text { (TENS) }\end{array}$ & Topical & Hematol. & HSCT & $\mathrm{P}$ & $\begin{array}{c}\text { Pimenta } \\
2012 \\
{[43]}\end{array}$ & $\mathrm{N}(1)$ & III & NGP & \\
\hline $\begin{array}{l}\text { Domiciliary } \\
\text { humidification }\end{array}$ & Topical & $\mathrm{H} \& \mathrm{~N}$ & $\begin{array}{l}\text { RT or } \\
\text { RT-CT }\end{array}$ & $\mathrm{P}$ & $\begin{array}{c}\text { Macann } \\
2014 \\
{[44]}\end{array}$ & $\mathrm{Y}(1)$ & III & NGP & \\
\hline $\begin{array}{l}\text { N-acetyl cysteine } \\
\text { (NAC) }\end{array}$ & Systemic & Hematol. & HSCT & $\mathrm{P}$ & $\begin{array}{c}\text { Moslehi } \\
2014 \\
{[45]}\end{array}$ & $\mathrm{Y}(1,2)$ & II & NGP & \\
\hline
\end{tabular}

Non-RCT studies key: 3. Non-RCT, 4. Cohort, 5. Before and after, 6. Case control studies, 7. Cross sectional, 8. Case series, 9. Case report, 10. Expert opinion

Effectiveness key: 1-Mucositis severity; 2-Mucositis duration; 3-Pain severity; 4-Pain duration

$H S C T$ hematopoietic stem cell transplant; $H \& N$ head and neck; $R T$ radiotherapy; $C T$ chemotherapy; hematol hematological; $P$ prevention; $Y$ yes, effective; $N$ no, ineffective; $N G P$ no guideline possible; ${ }^{\wedge}$ pediatric

preventing OM [Table 4] [43]. Interestingly, this RCT included another experimental group in which patients were treated with electrostimulation to increase saliva secretion. However, the study sample was small and the data are limited [43].

Another RCT studied the efficacy of artificial humidification in $\mathrm{H} \& \mathrm{~N}$ cancer patients treated with either RT or RT-CT was published [Table 4] [44]. This study concluded that humidification was beneficial for the prevention of OM. Blinding was not applied in the artificial humidification study; however, it is understandable that it is impossible to blind the patient to this treatment modality [44]. Due to the limited data, no guideline is possible.

\section{$\mathrm{N}$-acetyl cysteine (NAC) - hematologic cancer - HSCT - prevention}

\section{Guideline: No guideline possible (LoE II)}

Asingle RCT evaluated the effectiveness of intravenous $\mathrm{N}$-acetyl cysteine (NAC) for the prevention of $\mathrm{OM}$ in hematologic cancer patients undergoing HSCT [Table 4] [45]. The incidence of severe OM (grades 3-4) was significantly lower and the mean duration of $\mathrm{OM}$ was significantly shorter in the NAC group compared with the control group. This evidence did not meet the threshold to determine a guideline.

\section{Curcumin}

Curcumin has antioxidant, free-radical scavenging, and anti-inflammatory properties and has been used in traditional natural herbal medicine for management of wound healing and burns [46]. Furthermore, curcumin was reported to have anti-tumor properties [47]. Curcumin is obtained from the rhizome of Curcuma longa, a member of the Zingiberaceae family.

\section{Curcumin (topical) - H\&N cancer - RT - treatment}

\section{Guideline: No guideline possible (LoE III)}

A single RCT investigated curcumin in $\mathrm{H} \& \mathrm{~N}$ cancer patient treated with RT [Table 5] [48]. This small RCT compared Curcuma longa gel with placebo and found it to be effective for reducing the severity of OM. Another RCT in an undefined cancer population compared Indian turmeric combined with honey to a control group that received no treatment [49]. Considering the limited information about the patient population, it is impossible to align these data to any specific clinical setting or to conclude about the efficacy of turmeric.

Two comparator RCTs were conducted in H\&N cancer patients. The first RCT compared turmeric with povidone iodine in patients treated with RT or RT-CT and found turmeric to be effective in preventing OM [50]. The second RCT 


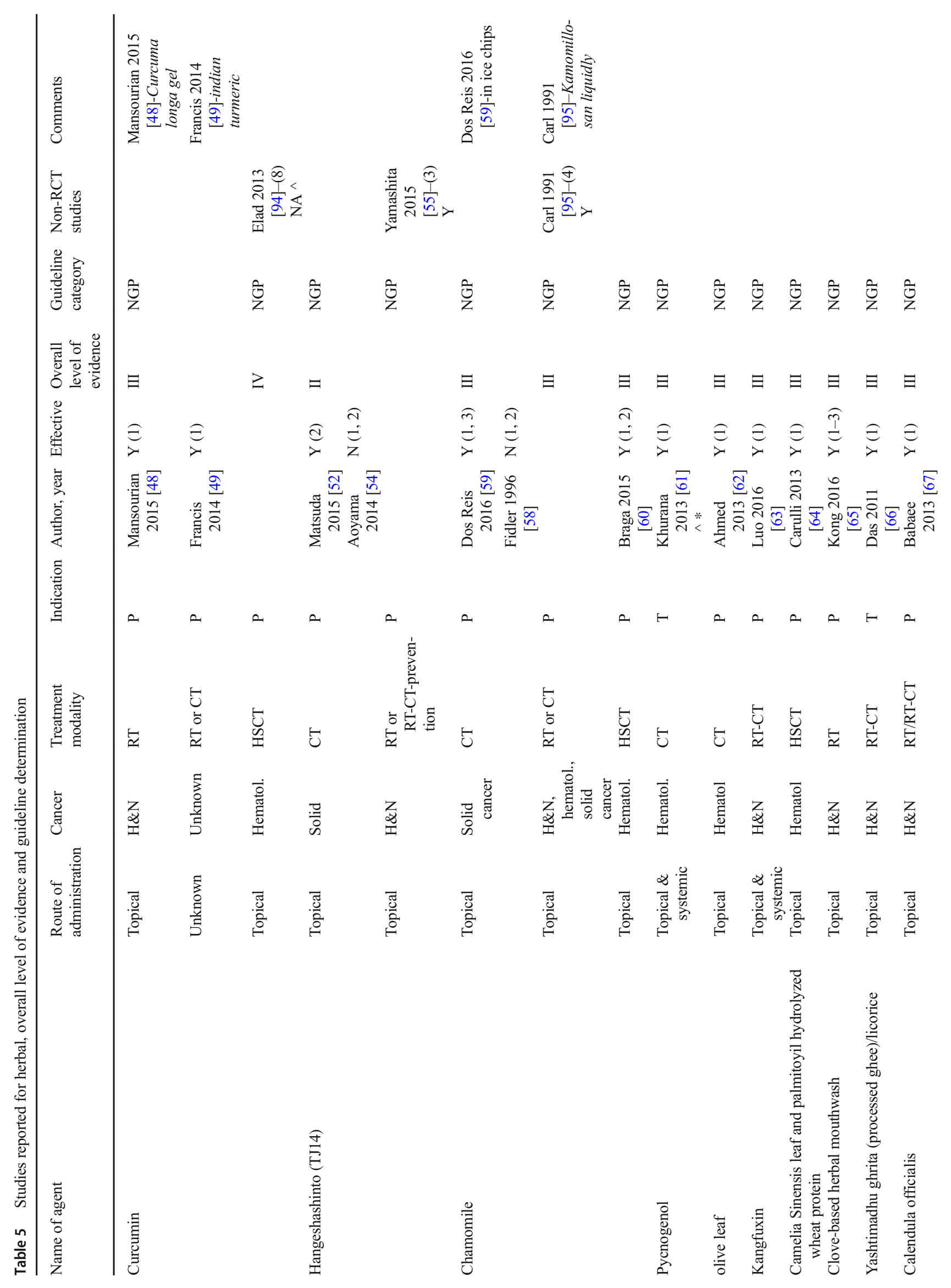




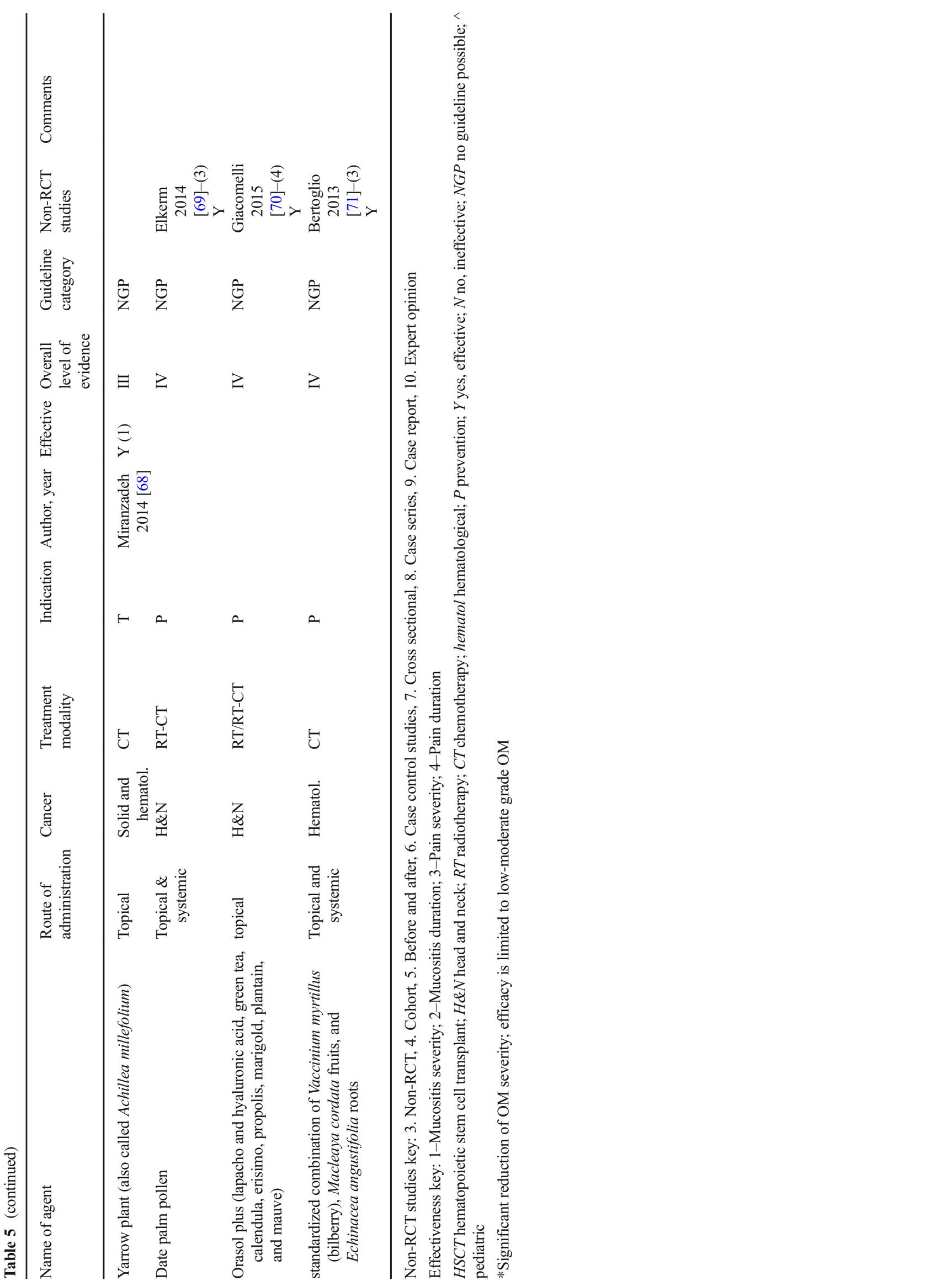


compared topical curcumin $0.004 \%$ mouthwash with $0.2 \%$ chlorhexidine for the treatment of established RT-CT induced OM [51]. Since these studies did not use a placebo group, they were not used for this analysis of curcumin efficacy.

\section{Hangeshashinto (TJ14)}

Hangeshashinto is a traditional Japanese herbal medicine. It is a mixture of seven herbs including pinellia tuber, scutellaria root, glycyrrhiza, jujube, ginseng, processed ginger, and Coptis rhizome [52]. It reduces the level of prostaglandin E2 and affects the cyclooxygenase activity in oral keratinocytes in hamsters [53]. These properties were the basis for the hypothesis that Hangeshashinto may prevent OM.

\section{Hangeshashinto (topical)- solid cancer - CT - prevention}

\section{Guideline: No guideline possible (LoE II)}

This review identified 2 RCTs which assessed topical Hangeshashinto for the prevention of $\mathrm{OM}$ in patients with gastric cancer, and presented opposing conclusions [Table 5] [52,54]. Both studies used $2.5 \mathrm{~g}$ in $50 \mathrm{~mL}$ water three times a day. Considering the conflicting results, no guideline was possible in this clinical setting.

Hangeshashinto was also used in a comparative study in $\mathrm{H} \& \mathrm{~N}$ cancer patients to prevent $\mathrm{OM}$ associated with either RT or RT-CT [Table 5] [55]. The study reported that Hangeshashinto was effective in reducing the severity of $\mathrm{OM}$ and improved the completion rate of $\mathrm{CT}$ cycle. Due to limited evidence, no guideline is possible for this category.

\section{Chamomile}

Chamomile is one of the most popular medicinal plants in the world due to its assumed antiinflammatory properties. Its anti-inflammatory activities are mediated by the inhibition of lipopolysaccharide-induced prostaglandin E [2] release and by reduction of cyclooxygenase (COX)-2 enzyme activity. Interestingly, chamomile does not affect the levels of COX-1 [56,57]. Chamomile was also reported to have antibacterial and anti-fungal properties [58].

\section{Chamomile (topical) - solid cancer - CT - prevention}

\section{Guideline: No guideline possible (LoE III)}

A RCT was identified about chamomile for the prevention of $\mathrm{OM}$ in patients with solid cancer treated with CT [Table 5] [59]. The chamomile was delivered as ice chips and was compared to a control group that was treated with ice chips only. This RCT

Table 6 Studies reported for probiotics and miscellaneous agents, overall level of evidence, and guideline determination

\begin{tabular}{|c|c|c|c|c|c|c|c|c|c|}
\hline Name of agent & $\begin{array}{l}\text { Route of } \\
\text { administration }\end{array}$ & Cancer & $\begin{array}{l}\text { Treatment } \\
\text { modality }\end{array}$ & Indication & Author, year & Effective & $\begin{array}{l}\text { Overall level } \\
\text { of evidence }\end{array}$ & $\begin{array}{l}\text { Guideline } \\
\text { category }\end{array}$ & $\begin{array}{l}\text { Non-RCT } \\
\text { studies }\end{array}$ \\
\hline $\begin{array}{l}\text { Lactobacillus brevis } \mathrm{cd} 2 \\
\text { lozenges }\end{array}$ & $\begin{array}{l}\text { Topical \& } \\
\quad \text { systemic }\end{array}$ & $\mathrm{H} \& \mathrm{~N}$ & RT-CT & $\mathrm{P}$ & $\begin{array}{l}\text { Sharma } \\
2012 \text { [73] }\end{array}$ & $\mathrm{Y}(1)$ & II & NGP & \\
\hline Ag013 bacteria & Topical & $\mathrm{H} \& \mathrm{~N}$ & $\mathrm{CT}$ & $\mathrm{P}$ & $\begin{array}{l}\text { Limaye } \\
2013 \text { [72] }\end{array}$ & $\mathrm{Y}(1,2)$ & III & NGP & \\
\hline $\begin{array}{l}\text { Phenylbutyrate } \\
\text { gelformulation } \\
\text { mouthwash }\end{array}$ & Topical & $\mathrm{H} \& \mathrm{~N}$ & RT/RT-CT & $\mathrm{T}$ & $\begin{array}{c}\text { Yen } 2012 \\
{[74]}\end{array}$ & $\mathrm{Y}(1)$ & III & NGP & \\
\hline Phenytoin & Topical & $\mathrm{H} \& \mathrm{~N}$ & RT/RT-CT & $\mathrm{P}$ & $\begin{array}{l}\text { Baharvand } \\
2015 \text { [75] }\end{array}$ & $\mathrm{N}$ & III & NGP & \\
\hline Oral beta-glucan & Systemic & Solid & $\mathrm{CT}$ & $\mathrm{P}$ & & & IV & NGP & $\begin{array}{r}\text { Karaca } 2014 \\
{[76]-(6) \mathrm{Y}}\end{array}$ \\
\hline Platelet gel supernatent & Topical & $\mathrm{H} \& \mathrm{~N}$ & RT/RT-CT & $\mathrm{P}$ & & & III & NGP & $\begin{array}{r}\text { Bonfili } 2015 \\
\text { [77]-(3) Y }\end{array}$ \\
\hline Ankaferd hemostat & $\begin{array}{l}\text { Topical \& } \\
\quad \text { systemic }\end{array}$ & Hematol. & $\mathrm{CT}$ & $\mathrm{T}$ & & & IV & NGP & $\begin{array}{l}\text { Atay } 2015 \\
{[78]-(8) \mathrm{Y}}\end{array}$ \\
\hline
\end{tabular}

Non-RCT studies key: 3. Non-RCT, 4. Cohort, 5. Before and after, 6. Case control studies, 7. Cross sectional, 8. Case series, 9. Case report, 10. Expert opinion

Effectiveness key: 1-Mucositis severity; 2-Mucositis duration; 3-Pain severity; 4-Pain duration

$H S C T$ hematopoietic stem cell transplant; $H \& N$ head and neck; $R T$ radiotherapy; $C T$ chemotherapy; hematol hematological; $P$ prevention; $Y$ yes, effective; $N$ no, ineffective; $N G P$ no guideline possible; ${ }^{\wedge}$ pediatric 
Table 7 Interventions for which the evidence and guideline are unchanged, based on existing literature (Adapted from Yarom 2013, Jensen 2013) [5,6]

\begin{tabular}{|c|c|c|c|c|c|}
\hline Aim & Agent & $\begin{array}{l}\text { Route of } \\
\text { administration }\end{array}$ & patient population & $\begin{array}{l}\text { Treatment } \\
\text { modality }\end{array}$ & Guideline \\
\hline $\mathrm{P}$ & Aloe vera* & Systemic (PO) & $\mathrm{H} \& \mathrm{~N}$ cancer & RT or RT-CT & NGP \\
\hline $\mathrm{P}$ & Quing Wei San or Yu Nu Jian & Topical & Hematol. & NS & NGP \\
\hline $\mathrm{P}$ & Indigowood root & Topical \& systemic & $\mathrm{H} \& \mathrm{~N}$ cancer & RT or RT-CT & NGP \\
\hline $\mathrm{T}$ & MF5232 & Systemic (PO) & $\mathrm{H} \& \mathrm{~N}$ cancer & RT-CT & NGP \\
\hline $\mathrm{P}$ & Rhodiola algida & Systemic (PO) & Solid cancer & CT & NGP \\
\hline $\mathrm{T}$ & $\begin{array}{l}\text { Compound collagen, amino-acids and sodium } \\
\text { hyaluronate }\end{array}$ & Topical & $\begin{array}{l}\mathrm{H} \& \mathrm{~N} \text { cancer, hematol. cancer, solid } \\
\text { cancer }\end{array}$ & $\begin{array}{l}\text { RT or RT-CT or } \\
\text { CT }\end{array}$ & NGP \\
\hline $\mathrm{P}$ & Wobe-mugos E & Systemic (PO) & $\mathrm{H} \& \mathrm{~N}$ cancer & RT & NGP \\
\hline $\mathrm{P}$ & Manuka \& kanuka oils & Topical \& systemic & $\mathrm{H} \& \mathrm{~N}$ cancer & RT & NGP \\
\hline $\mathrm{P}$ & Allopurinol & Systemic (PO) & Hematol. cancer, solid cancer & $\mathrm{CT}$ & NGP \\
\hline $\mathrm{P}$ & Allopurinol & Topical & Solid cancer & $\mathrm{CT}$ & NGP \\
\hline $\mathrm{P}$ & Papayor & Topical & $\mathrm{H} \& \mathrm{~N}$ cancer & RT & NGP \\
\hline $\mathrm{P}$ & RT (timing) & NA & $\mathrm{H} \& \mathrm{~N}$ cancer & RT & NGP \\
\hline $\mathrm{P}$ & Pilocarpine & Systemic (PO) & $\mathrm{H} \& \mathrm{~N}$ cancer & RT & $\begin{array}{c}\text { Suggestion } \\
\text { against }\end{array}$ \\
\hline $\mathrm{P}$ & Pilocarpine & Systemic (PO) & Hematol. cancer & HSCT & $\begin{array}{c}\text { Suggestion } \\
\text { against }\end{array}$ \\
\hline $\mathrm{P}$ & Propantheline & Systemic (PO) & Hematol. and solid cancers & HSCT & NGP \\
\hline $\mathrm{P}$ & Bethanechol & Systemic (PO) & $\mathrm{H} \& \mathrm{~N}$ cancer & RT & \\
\hline $\mathrm{P}$ & Tetrachlorodecaoxide & Systemic (PO) & Hematol. and solid cancers & $\mathrm{CT}$ & NGP \\
\hline $\mathrm{P}$ & PTX & Systemic (PO) & Hematol. cancer & HSCT & $\begin{array}{c}\text { Suggestion } \\
\text { against }\end{array}$ \\
\hline $\mathrm{P}$ & PTX & Systemic (IV) & Hematol. cancer & HSCT & NGP \\
\hline $\mathrm{P}$ & PTX & Systemic (PO) & Solid cancer & $\mathrm{CT}$ & NGP \\
\hline
\end{tabular}

$P$ prevention, $T$ treatment, $H \& N$ head and neck, $R T$ radiotherapy, $R T$-CT radiochemotherapy, Hematol. hematologic, $C T$ chemotherapy, $H S C T$ hematopoietic stem cell transplantation, $N G P$ no guideline possible, $P T X$ pentoxifylline, $P O$ per os, $I V$ intravenous

*A comparator RCT was published but was not contributory to the efficacy analysis-aloe vera vs benzydamine [96]

demonstrated that chamomile was effective in reducing $\mathrm{OM}$ severity and in relieving $\mathrm{OM}$-associated pain. This RCT is added to a previously reported RCT investigating chamomile in a similar clinical setting that also reported no benefit [58]. Due to conflicting evidence, no guideline was possible.

\section{Chamomile (topical) - hematologic cancer - HSCT - prevention}

\section{Guideline: No guideline possible (LoE III)}

Topical chamomile was studied for the prevention of OM in an additional clinical setting-patients undergoing HSCT [60]. This study compared 3 doses of Chamomilla recutita extract $(0.5 \%, 1 \%$, and $2 \%)$ with standard of care consisting of self-oral hygiene and $0.12 \% \mathrm{CHX}$. The authors reported that chamomile $1 \%$ extract significantly reduced the severity and duration of
OM. Due to limited evidence no guideline was possible.

\section{Other herbal remedies}

A variety of herbal remedies were reported for the prevention or treatment of $\mathrm{OM}$ since the previous guidelines update [Table 5]. This includes pycnogenol [61], olive leaf [62], Kangfuxin [63], Camelia Sinensis leaf and and Palmitoyil hydrolyzed wheat protein (Baxidil Onco) [64], clove-based herbal compound [65], Yashtimadhu ghrita (processed ghee)/Licorice [66], Calendula [67], and Yarrow plant (also called Achillea millefolium) [68]. Each intervention had a single RCT. Lower levels of evidence were published for date palm pollen [69], mixed compound based on Lapacho and hyaluronic acid, green tea, Erisimo, propolis, Marigold, Plantain, and Mauve (OraSol Plus) [70], and compound based on Vaccinium myrtillus (bilberry), Macleaya cordata fruits, and Echinacea angustifolia roots 
(Samital) [71]. Due to the limited evidence, no guideline is possible for these compounds.

\section{Probiotics and miscellaneous agents}

Protean interventions were assessed for either prevention or treatment of OM [Table 6]. Two studies on probiotics were focused on lactobacillus and lactococcus that were administered either systemically or topically $[72,73]$. Both studies showed efficacy in preventing OM in H\&N cancer patients. Considering the limited data for each of these probiotics, no guideline is possible.

Miscellaneous agents that were tested for the management of $\mathrm{OM}$ and included in this systematic review are Phenylbutyrate gelformulation mouthwash [72-74], phenytoin [75], oral beta-glucan [76] and platelet gel supernatant [77], and ankaferd hemostat [Table 6] [78]. No guideline was possible for any of these interventions.

Interventions for which evidence was reported prior to 2011 (addressed in the previous guidelines), and no new evidence was reported since are listed briefly as summarized in the 2013 Guidelines Update [Table 7].

\section{Discussion}

Herbal remedies have been used for centuries for the healing of numerous conditions in different cultures worldwide [79]. They are the imprint of the local cultures, unique regional vegetation, and ancient medicine knowledge. Herbal remedies are becoming more accessible to a larger community as global communication and interest in alternative medicine increases. With modernized industrial techniques, these agents are available for larger populations. This manuscript covers natural agents, probiotics, and modalities that are affecting the moistening in the mouth and a group of miscellaneous agents. Two new guidelines were made based on this systematic review: a Suggestion in favor for honey, and a Suggestion against chewing gum.

Honey, as a combination protocol of topical and systemic administration, is suggested to prevent $\mathrm{OM}$ in patients with H\&N cancer treated with RT or RT-CT [18-23]. This new guideline is based on several RCTs showing positive effects for honey. However, since some of these RCTs had a mixed patient population, small sample size, and different sources for the honey, the guidelines can only be confined to a Suggestion. Notably, both RCTs studying topical Manuka honey were negative, and it is unclear if a combined topical and systemic application of Manuka honey will be effective in preventing $\mathrm{OM}$ in $\mathrm{H} \& \mathrm{~N}$ cancer patients.
Importantly, honey has a cariogenic effect and it adheres to the teeth. . Although the prevention of OM is limited for the duration of the RT, if the honey is applied repeatedly on a daily basis for a longer period, such deleterious effects may occur [80,81] Accordingly, patients who are applying honey to prevent $\mathrm{OM}$ should be on a strict oral hygiene program to prevent dental caries [82].

The systematic review yielded a new guideline for chewing gum. Based on the evidence available from 2 RCTs in pediatric patients, a suggestion against the use of chewing gum was made for the prevention of $\mathrm{OM}$ in patients with hematologic or solid cancer treated with CT. This guideline does not preclude the use of chewing gum for any other purpose: saliva production, flavor, refreshment, or simply joy. This guideline reflects the fact that chewing gum will not prevent $\mathrm{OM}$ in this clinical setting.

Other changes in this section compared with the 2013 guidelines update include identifying evidence for new interventions (propolis), artificial humidification, or for a new clinical setting (curcumin, traumeel, Hangeshashinto). Unfortunately, this new evidence did not culminate into a guideline.

The scope of "miscellaneous" treatments for the management of OM may extend to medical devices, such as appliances to reduce RT-associated OM $[83,84]$. The group felt that this topic would benefit from a dedicated systematic review, although it was touched on in the previous guidelines update [5]. Likewise, impact of cancer treatment modality and radiation technique on outcomes and toxicity of patients are not included in this systematic review as OM was a secondary endpoint. Rarely, studies on the modification to the cancer therapy protocol addressed $\mathrm{OM}$ as the primary endpoint [85-87].

Several studies were published since the cut-off date of this literature review, which refers to propolis, honey, Glycyrrhiza aqueous extract and licorice. Propolis was studied in a RCT in breast cancer patients receiving doxorubicin and cyclophosphamide. The results showed that propolis plus sodium bicarbonate was significantly more effective than sodium bicarbonate alone in preventing $\mathrm{OM}$ [88]. As this study reports about a clinical setting that was not reported previously, this is considered to be initial information that needs confirmation in the future. Propolis was also studied as part of a mixture of 4 natural agents: propolis, Aloe vera, calendula, and chamomile [89]. In this RCT in H\&N cancer patients receiving RT, the mixture was reported to be superior to placebo in preventing OM. A recent RCT investigated honey to prevent $\mathrm{OM}$ in a single-blinded design [90]. This study concluded that honey was effective in preventing $\mathrm{OM}$ in patients with leukemia treated with $\mathrm{CT}$; however, considering the variation in the mode of application, and the small sample size, the collective evidence about honey in this 
clinical setting did not cross the threshold for a guideline. Glycyrrhiza aqueous extract was studied in a single small RCT, and showed positive results. This evidence was too limited to set a guideline [91]. Licorice in mucoadhesive vehicle was reported to be as effective as triamcinolone acetonide in reducing $\mathrm{OM}$ severity in $\mathrm{H} \& \mathrm{~N}$ cancer patients treated with RT only [92]. As this RCT was designed as a comparator study without a placebo arm, the results are not contributory to the efficacy analysis in this study.

In summary, the MASCC/ISOO guideline update suggests applying honey, combined topically and systemically, for the prevention of OM in H\&N cancer patients treated with either RT or RT-CT. Chewing gum is not suggested for the prevention of $\mathrm{OM}$ in pediatric patients with hematological or solid cancer treated with $\mathrm{CT}$. These guidelines are subject to further updates pending results of future published studies.

\section{Compliance with ethical standards}

Conflict of interest Per MASCC Guidelines Policy, employees of commercial entities were not eligible to serve on this MASCC Guidelines Panel.

The authors disclose no conflict of interest (NY, AH, AA, SBJ, MG, HIH, AK, AM, JO, MP, NMN, TR, ASL, NST, EZ, VR, AV, KF, AB). PB has served an advisory role for AstraZeneca, Helsinn, and Kyowa Kyrin and received grants from Merck, Kyowa Kyrin, and Roche. RVL has served as a consultant for Colgate Oral Pharmaceuticals, Galera Therapeutics, Ingalfarma SA, Monopar Therapeutics, Mundipharma, and Sucampo Pharma; has received research support to his institution from Galera Therapeutics, Novartis, Oragenics, and Sucampo Pharma; and has received stock in Logic Biosciences. SE discloses no conflict of interest in regards to the subject matter, and served as a consultant for Falk Pharma outside the submitted work.

\section{References}

1. Elad S, Zadik Y, Yarom N (2017) Oral complications of nonsurgical cancer therapies. Atlas Oral Maxillofac Surg Clin North Am 25: 133-147

2. Keefe DM, Schubert MM, Elting LS, Sonis ST, Epstein JB, RaberDurlacher JE, Migliorati CA, McGuire D, Hutchins RD, Peterson DE, Mucositis Study Section of the Multinational Association of Supportive Care in Cancer and the International Society for Oral Oncology (2007) Updated clinical practice guidelines for the prevention and treatment of mucositis. Cancer 109:820-831

3. Rubenstein EB, Peterson DE, Schubert M, Keefe D, McGuire D, Epstein J, Elting LS, Fox PC, Cooksley C, Sonis ST, Mucositis Study Section of the Multinational Association for Supportive Care in Cancer, International Society for Oral Oncology (2004) Clinical practice guidelines for the prevention and treatment of cancer therapy-induced oral and gastrointestinal mucositis. Cancer 100:2026-2046

4. Lalla RV, Bowen J, Barasch A, Elting L, Epstein J, Keefe DM, McGuire D, Migliorati C, Nicolatou-Galitis O, Peterson DE, Raber-Durlacher JE, Sonis ST, Elad S, Mucositis Guidelines Leadership Group of the Multinational Association of Supportive
Care in Cancer and International Society of Oral Oncology (MASCC/ISOO) (2014) MASCC/ISOO clinical practice guidelines for the management of mucositis secondary to cancer therapy. Cancer 120:1453-1461

5. Jensen SB, Jarvis V, Zadik Y et al (2013) Systematic review of miscellaneous agents for the management of oral mucositis in cancer patients. Support Care Cancer 21:3223-3232

6. Yarom N, Ariyawardana A, Hovan A, Barasch A, Jarvis V, Jensen SB, Zadik Y, Elad S, Bowen J, Lalla RV, Mucositis Study Group of the Multinational Association of Supportive Care in Cancer/ International Society of Oral Oncology (MASCC/ISOO) (2013) Systematic review of natural agents for the management of oral mucositis in cancer patients. Support Care Cancer 21:3209-3221

7. Yarom N, Hovan A, P. B, et al: Systematic review of natural and miscellaneous agents for the management of oral mucositis in cancer patients and Clinical Practice Guidelines - Part 1: vitamins, minerals and nutritional supplements. Support Care Cancer, 2019

8. Ranna V, Cheng KKF, Castillo DA et al (2019) Development of the MASCC/ISOO clinical practice guidelines for mucositis: an overview of the methods. Support Care Cancer

9. Somerfield MPJ, Pfister D, Bennett C, Recht A, Smith T, Weeks J, Winn R, Duraant J (2000) ASCO clinical practice guidelines: process, progress, pitfalls, and prospects. Classic Papers and Current Comments 4:881-886

10. Hadorn DC, Baker D, Hodges JS, Hicks N (1996) Rating the quality of evidence for clinical practice guidelines. J Clin Epidemiol 49: 749-754

11. Molan PC (2006) The evidence supporting the use of honey as a wound dressing. Int J Low Extrem Wounds 5:40-54

12. Bang LM, Buntting C, Molan P (2003) The effect of dilution on the rate of hydrogen peroxide production in honey and its implications for wound healing. J Altern Complement Med 9:267-273

13. Willix DJ, Molan PC, Harfoot CG (1992) A comparison of the sensitivity of wound-infecting species of bacteria to the antibacterial activity of manuka honey and other honey. J Appl Bacteriol 73: 388-394

14. Bardy J, Molassiotis A, Ryder WD, Mais K, Sykes A, Yap B, Lee L, Kaczmarski E, Slevin N (2012) A double-blind, placebo-controlled, randomised trial of active manuka honey and standard oral care for radiation-induced oral mucositis. Br J Oral Maxillofac Surg 50:221-226

15. Hawley P, Hovan A, McGahan CE, Saunders D (2014) A randomized placebo-controlled trial of manuka honey for radiation-induced oral mucositis. Support Care Cancer 22:751-761

16. Jayalekshmi JL, Lakshmi R, Mukerji A (2016) Honey on oral mucositis: a randomized controlled trial. Gulf J Oncolog 1:30-37

17. Yamauchi K, Kogashiwa Y, Moro Y et al (2014) The effect of topical application of royal jelly on chemoradiotherapy-induced mucositis in head and neck cancer: a preliminary study. Int J Otolaryngol 2014:974967

18. Biswal BM, Zakaria A, Ahmad NM (2003) Topical application of honey in the management of radiation mucositis: a preliminary study. Support Care Cancer 11:242-248

19. Jayachandran S, Balaji N (2012) Evaluating the effectiveness of topical application of natural honey and benzydamine hydrochloride in the management of radiation mucositis. Indian J Palliat Care 18:190-195

20. Maiti PK, Ray A, Mitra TN, Jana U, Bhattacharya J, Ganguly S (2012) The effect of honey on mucositis induced by chemoradiation in head and neck cancer. J Indian Med Assoc 110:453-456

21. Motallebnejad M, Akram S, Moghadamnia A et al (2008) The effect of topical application of pure honey on radiation-induced mucositis: a randomized clinical trial. J Contemp Dent Pract 9: $40-47$ 
22. Rashad UM, Al-Gezawy SM, El-Gezawy E et al (2009) Honey as topical prophylaxis against radiochemotherapy-induced mucositis in head and neck cancer. J Laryngol Otol 123:223-228

23. Samdariya S, Lewis S, Kauser H, Ahmed I, Kumar D (2015) A randomized controlled trial evaluating the role of honey in reducing pain due to radiation induced mucositis in head and neck Cancer patients. Indian J Palliat Care 21:268-273

24. Erdem O, Gungormus Z (2014) The effect of royal jelly on oral mucositis in patients undergoing radiotherapy and chemotherapy. Holist Nurs Pract 28:242-246

25. Khanal B, Baliga M, Uppal N (2010) Effect of topical honey on limitation of radiation-induced oral mucositis: an intervention study. Int J Oral Maxillofac Surg 39:1181-1185

26. Raeessi MA, Raeessi N, Panahi Y et al (2014) "Coffee plus honey" versus "topical steroid" in the treatment of chemotherapy-induced oral mucositis: a randomised controlled trial. BMC Complement Altern Med 14:293

27. Abdulrhman M, Elbarbary NS, Ahmed Amin D, Saeid Ebrahim R (2012) Honey and a mixture of honey, beeswax, and olive oilpropolis extract in treatment of chemotherapy-induced oral mucositis: a randomized controlled pilot study. Pediatr Hematol Oncol 29:285-292

28. Mohamed SA, Shebl A, Weheida SM (2012) The effect of topical application of honey on management of chemotherapy induced oral stomatitis. Life Science Journal 9:5128-5134

29. Oryan A, Alemzadeh E, Moshiri A (2018) Potential role of propolis in wound healing: biological properties and therapeutic activities. Biomed Pharmacother 98:469-483

30. Kuropatnicki AK, Szliszka E, Krol W (2013) Historical aspects of propolis research in modern times. Evid Based Complement Alternat Med 2013:964149

31. AkhavanKarbassi MH, Yazdi MF, Ahadian H, SadrAbad M (2016) Randomized double blind placebo controlled trial of propolis for oral mucositis in patients receiving chemotherapy for head and neck cancer. Asian Pac J Cancer Prev 17:3611-3614

32. Javadzadeh Bolouri A, Pakfetrat A, Tonkaboni A et al (2015) Preventing and therapeutic effect of propolis in radiotherapy induced mucositis of head and neck cancers: a triple-blind, randomized, placebo-controlled trial. Iran J Cancer Prev 8:e4019

33. Tomazevic T, Jazbec J (2013) A double blind randomised placebo controlled study of propolis (bee glue) effectiveness in the treatment of severe oral mucositis in chemotherapy treated children. Complement Ther Med 21:306-312

34. Noronha VR, Araujo GS, Gomes RT, Iwanaga SH, Barbosa MC, Abdo EN, Ferreira e Ferreira E, Viana Campos AC, Souza AA, Abreu SR, Santos VR (2014) Mucoadhesive propolis gel for prevention of radiation-induced oral mucositis. Curr Clin Pharmacol 9: 359-364

35. Sencer SF, Zhou T, Freedman LS et al (2012) Traumeel S in preventing and treating mucositis in young patients undergoing SCT: a report of the Children's oncology group. Bone Marrow Transplant 47:1409-1414

36. Oberbaum M, Yaniv I, Ben-Gal Y et al (2001) A randomized, controlled clinical trial of the homeopathic medication TRAUMEEL $\mathrm{S}$ in the treatment of chemotherapy-induced stomatitis in children undergoing stem cell transplantation. Cancer 92:684-690

37. Steinmann D, Eilers V, Beynenson D, Buhck H, Fink M (2012) Effect of Traumeel S on pain and discomfort in radiation-induced oral mucositis: a preliminary observational study. Altern Ther Health Med 18:12-18

38. Pedersen AML, Sorensen CE, Proctor GB et al (2018) Salivary secretion in health and disease. J Oral Rehabil 45:730-746

39. Bodner L, Dayan D (1995) Epithelium and connective tissue regeneration during palatal wound healing in desalivated rats-a comparative study. Comp Biochem Physiol A Physiol 111:415-419
40. Edgar WM (1998) Sugar substitutes, chewing gum and dental caries-a review. Br Dent J 184:29-32

41. Eghbali A, Taherkhanchi B, Bagheri B, Sadeghi Sedeh B (2016) Effect of chewing gum on oral mucositis in children undergoing chemotherapy: a randomized controlled study. Iran J Ped Hematol Oncol 6:9-14

42. Gandemer V, Le Deley MC, Dollfus C et al (2007) Multicenter randomized trial of chewing gum for preventing oral mucositis in children receiving chemotherapy. J Pediatr Hematol Oncol 29:8694

43. Pimenta Amaral TM, Campos CC, Moreira dos Santos TP et al (2012) effect of salivary stimulation therapies on salivary flow and chemotherapy-induced mucositis: a preliminary study. Oral Surg Oral Med Oral Pathol Oral Radiol 113:628-637

44. Macann A, Fua T, Milross CG et al (2014) Phase 3 trial of domiciliary humidification to mitigate acute mucosal toxicity during radiation therapy for head-and-neck cancer: first report of Trans Tasman Radiation Oncology Group (TROG) 07.03 RadioHUM study. Int J Radiat Oncol Biol Phys 88:572-579

45. Moslehi A, Taghizadeh-Ghehi M, Gholami K, Hadjibabaie M, Jahangard-Rafsanjani Z, Sarayani A, Javadi M, Esfandbod M, Ghavamzadeh A (2014) N-acetyl cysteine for prevention of oral mucositis in hematopoietic SCT: a double-blind, randomized, placebo-controlled trial. Bone Marrow Transplant 49:818-823

46. Mohanty C, Sahoo SK (2017) Curcumin and its topical formulations for wound healing applications. Drug Discov Today 22:1582 1592

47. Bachmeier BE, Killian PH, Melchart D (2018) The role of Curcumin in prevention and management of metastatic disease. Int J Mol Sci 19

48. Mansourian A, Amanlou M, Shirazian S et al (2015) The effect of "Curcuma Longa" topical gel on radiation-induced oral mucositis in patients with head and neck cancer. International Journal of Radiation Research 13:269-274

49. Francis M, Williams S (2014) Effectiveness of Indian turmeric powder with honey as complementary therapy on oral mucositis : a nursing perspective among cancer patients in Mysore. Nurs J India 105:258-260

50. Rao S, Dinkar C, Vaishnav LK, Rao P, Rai MP, Fayad R, Baliga MS (2014) The Indian spice turmeric delays and mitigates radiationinduced oral mucositis in patients undergoing treatment for head and neck cancer: an investigational study. Integr Cancer Ther 13: 201-210

51. Patil K, Guledgud MV, Kulkarni PK et al (2015) Use of curcumin mouthrinse in radio-chemotherapy induced oral mucositis patients: a pilot study. J Clin Diagn Res 9:Zc59-Zc62

52. Matsuda C, Munemoto Y, Mishima H, Nagata N, Oshiro M, Kataoka M, Sakamoto J, Aoyama T, Morita S, Kono T (2015) Double-blind, placebo-controlled, randomized phase II study of TJ-14 (Hangeshashinto) for infusional fluorinated-pyrimidinebased colorectal cancer chemotherapy-induced oral mucositis. Cancer Chemother Pharmacol 76:97-103

53. Kono T, Kaneko A, Matsumoto C et al (2012) Amelioration of 5fluorouracil-induced oral mucositis in hamsters by TJ-14 (Hangeshashinto), inhibitor of inducible prostaglandin E2 and proinflammatory cytokines. Gastroenterology 142:S673

54. Aoyama T, Nishikawa K, Takiguchi N, Tanabe K, Imano M, Fukushima R, Sakamoto J, Oba MS, Morita S, Kono T, Tsuburaya A (2014) Double-blind, placebo-controlled, randomized phase II study of TJ-14 (hangeshashinto) for gastric cancer chemotherapy-induced oral mucositis. Cancer Chemother Pharmacol 73:1047-1054

55. Yamashita T, Araki K, Tomifuji M, Kamide D, Tanaka Y, Shiotani A (2015) A traditional Japanese medicine-Hangeshashinto (TJ14)-alleviates chemoradiation-induced mucositis and improves rates of treatment completion. Support Care Cancer 23:29-35 
56. Srivastava JK, Pandey M, Gupta S (2009) Chamomile, a novel and selective COX-2 inhibitor with anti-inflammatory activity. Life Sci 85:663-669

57. Srivastava JK, Shankar E, Gupta S (2010) Chamomile: a herbal medicine of the past with bright future. Mol Med Rep 3:895-901

58. Fidler P, Loprinzi CL, O'Fallon JR, Leitch JM, Lee JK, Hayes DL, Novotny P, Clemens-Schutjer D, Bartel J, Michalak JC (1996) Prospective evaluation of a chamomile mouthwash for prevention of 5-FU-induced oral mucositis. Cancer 77:522-525

59. Dos Reis PE, Ciol MA, de Melo NS, Figueiredo PT, Leite AF, Manzi Nde M (2016) Chamomile infusion cryotherapy to prevent oral mucositis induced by chemotherapy: a pilot study. Support Care Cancer 24:4393-4398

60. Braga FT, Santos AC, Bueno PC, Silveira RC, Santos CB, Bastos JK, Carvalho EC (2015) Use of Chamomilla recutita in the prevention and treatment of oral mucositis in patients undergoing hematopoietic stem cell transplantation: a randomized, controlled. Phase II Clinical Trial Cancer Nurs 38:322-329

61. Khurana H, Pandey RK, Saksena AK, Kumar A (2013) An evaluation of vitamin $\mathrm{E}$ and pycnogenol in children suffering from oral mucositis during cancer chemotherapy. Oral Dis 19:456-464

62. Ahmed KM (2013) The effect of olive leaf extract in decreasing the expression of two pro-inflammatory cytokines in patients receiving chemotherapy for cancer. A randomized clinical trial. Saudi Dent J 25:141-147

63. Luo Y, Feng M, Fan Z et al (2016) Effect of Kangfuxin solution on chemo/radiotherapy-induced mucositis in nasopharyngeal carcinoma patients: a multicenter, prospective randomized phase III clinical study. Evid Based Complement Alternat Med 2016:8692343

64. Carulli G, Rocco M, Panichi A et al (2013) Treatment of oral mucositis in hematologic patients undergoing autologous or allogeneic transplantation of peripheral blood stem cells: a prospective, randomized study with a mouthwash containing camelia sinensis leaf extract. Hematol Rep 5:21-25

65. Kong M, Hwang DS, Yoon SW et al (2016) The effect of clovebased herbal mouthwash on radiation-induced oral mucositis in patients with head and neck cancer: a single-blind randomized preliminary study. Onco Targets Ther 9:4533-4538

66. Das D, Agarwal SK, Chandola HM (2011) Protective effect of Yashtimadhu (Glycyrrhiza glabra) against side effects of radiation/ chemotherapy in head and neck malignancies. Ayu 32:196-199

67. Babaee N, Moslemi D, Khalilpour M et al (2013) Antioxidant capacity of calendula officinalis flowers extract and prevention of radiation induced oropharyngeal mucositis in patients with head and neck cancers: a randomized controlled clinical study. Daru $21: 18$

68. Miranzadeh S, Adib-Hajbaghery M, Soleymanpoor L et al (2014) A new mouthwash for chemotherapy induced stomatitis. Nurs Midwifery Stud 3:e20249

69. Elkerm Y, Tawashi R (2014) Date palm pollen as a preventative intervention in radiation- and chemotherapy-induced oral mucositis: a pilot study. Integr Cancer Ther 13:468-472

70. Giacomelli I, Scartoni D, Fiammetta M, Baki M, Zei G, Muntoni C, Cappelli S, Greto D, Scoccianti S, Livi L (2015) Oral Lapachobased medication: an easy, safe, and feasible support to prevent and/or reduce oral mucositis during radiotherapy for head and neck cancer. Nutr Cancer 67:1247-1253

71. Bertoglio JC, Calderon S, Lesina B et al (2013) Effect of SAMITAL $(\mathrm{R})$ in the treatment of chemotherapy-induced mucositis in adult oncohematological patients. Future Oncol 9:1727-1732

72. Limaye SA, Haddad RI, Cilli F, Sonis ST, Colevas AD, Brennan MT, Hu KS, Murphy BA (2013) Phase 1b, multicenter, single blinded, placebo-controlled, sequential dose escalation study to assess the safety and tolerability of topically applied AG013 in subjects with locally advanced head and neck cancer receiving induction chemotherapy. Cancer 119:4268-4276
73. Sharma A, Rath GK, Chaudhary SP et al (2012) Lactobacillus brevis CD2 lozenges reduce radiation- and chemotherapy-induced mucositis in patients with head and neck cancer: a randomized double-blind placebo-controlled study. Eur J Cancer 48:875-881

74. Yen SH, Wang LW, Lin YH et al (2012) Phenylbutyrate mouthwash mitigates oral mucositis during radiotherapy or chemoradiotherapy in patients with head-and-neck cancer. Int J Radiat Oncol Biol Phys 82:1463-1470

75. Baharvand M, Hamian M, Moosavizadeh MA, Mortazavi A, Ameri A (2015) Phenytoin mouthwash to treat cancer therapy-induced oral mucositis: a pilot studyPrimary neuroendocrine carcinoma of breast: a rare tumor. Indian J Cancer 52:81-85

76. Karaca H, Bozkurt O, Ozaslan E, Baldane S, Berk V, Inanc M, Duran AO, Dikilitas M, Er O, Ozkan M (2014) Positive effects of oral beta-glucan on mucositis and leukopenia in colorectal cancer patients receiving adjuvant FOLFOX-4 combination chemotherapy. Asian Pac J Cancer Prev 15:3641-3644

77. Bonfili P, Gravina GL, Marampon F, Rughetti A, di Staso M, Dell'Orso L, Vittorini F, Moro R, la Verghetta ME, Parente S, Reale M, Ruggieri V, Franzese P, Tombolini V, Masciocchi C, di Cesare E (2017) Oral platelet gel supernatant plus supportive medical treatment versus supportive medical treatment in the management of radiation-induced oral mucositis: a matched explorative active control trial by propensity analysis. Am J Clin Oncol 40: 336-341

78. Atay MH, Aslan NA, Aktimur S et al (2015) Safety and efficacy of Ankaferd hemostat (ABS) in the chemotherapy-induced Oral Mucositis. Int J Hematol Oncol 3:166-171

79. Li L, Yao H, Wang J et al (2019) The role of Chinese Medicine in Health Maintenance and Disease Prevention: Application of Constitution Theory. Am J Chin Med:1-12

80. Bowen WH, Lawrence RA (2005) Comparison of the cariogenicity of cola, honey, cow milk, human milk, and sucrose. Pediatrics 116: 921-926

81. Fidler Mis N, Braegger C, Bronsky J et al (2017) Sugar in infants, children and adolescents: A Position Paper of the European Society for Paediatric Gastroenterology, Hepatology and Nutrition Committee on Nutrition. J Pediatr Gastroenterol Nutr 65:681-696

82. Santos-Silva AR, Rosa GB, Eduardo CP et al (2011) Increased risk for radiation-related caries in cancer patients using topical honey for the prevention of oral mucositis. Int J Oral Maxillofac Surg 40: 1335-1336; author reply 1235

83. Verrone JR, Alves FA, Prado JD, Marcicano Ad, de Assis Pellizzon AC, Damascena AS, Jaguar GC (2014) Benefits of an intraoral stent in decreasing the irradiation dose to oral healthy tissue: dosimetric and clinical features. Oral Surg Oral Med Oral Pathol Oral Radiol 118:573-578

84. Yangchen K, Siddharth R, Singh SV et al (2016) A pilot study to evaluate the efficacy of cerrobend shielding stents in preventing adverse radiotherapeutic effects in buccal carcinoma patients. J Cancer Res Ther 12:314-317

85. Al-Mamgani A, van Rooij P, Verduijn GM et al (2013) The impact of treatment modality and radiation technique on outcomes and toxicity of patients with locally advanced oropharyngeal cancer. Laryngoscope 123:386-393

86. Fleming S, Harrison SJ, Blombery P et al (2014) The choice of multiple myeloma induction therapy affects the frequency and severity of oral mucositis after melphalan-based autologous stem cell transplantation. Clin Lymphoma Myeloma Leuk 14:291-296

87. Wang ZH, Zhang SZ, Zhang ZY, Zhang CP, Hu HS, Tu WY, Kirwan J, Mendenhall WM (2012) Protecting the oral mucosa in patients with oral tongue squamous cell carcinoma treated postoperatively with intensity-modulated radiotherapy: a randomized study. Laryngoscope 122:291-298

88. Piredda M, Facchinetti G, Biagioli V et al (2017) Propolis in the prevention of oral mucositis in breast cancer patients receiving 
adjuvant chemotherapy: a pilot randomised controlled trial. Eur J Cancer Care (Engl) 26

89. Marucci L, Farneti A, Di Ridolfi P et al (2017) Double-blind randomized phase III study comparing a mixture of natural agents versus placebo in the prevention of acute mucositis during chemoradiotherapy for head and neck cancer. Head Neck 39:1761-1769

90. Khanjani Pour-Fard-Pachekenari A, Rahmani A, Ghahramanian A, Asghari Jafarabadi M, Onyeka TC, Davoodi A (2019) The effect of an oral care protocol and honey mouthwash on mucositis in acute myeloid leukemia patients undergoing chemotherapy: a singleblind clinical trial. Clin Oral Investig 23:1811-1821

91. Najafi S, Koujan SE, Manifar S, Kharazifard MJ, Kidi S, Hajheidary S (2017) Preventive effect of Glycyrrhiza Glabra extract on Oral Mucositis in patients under head and neck radiotherapy: a randomized clinical trial. J Dent (Tehran) 14:267-274

92. Ghalayani P, Emami H, Pakravan F et al (2017) Comparison of triamcinolone acetonide mucoadhesive film with licorice mucoadhesive film on radiotherapy-induced oral mucositis: a randomized double-blinded clinical trial. Asia Pac J Clin Oncol 13: e48-e56
93. Bahramnezhad F, Dehghan Nayeri N, Bassampour SS et al (2015) Honey and radiation-induced stomatitis in patients with head and neck cancer. Iran Red Crescent Med J 17:e19256

94. Elad S, Meidan I, Sellam G, Simaan S, Zeevi I, Waldman E, Weintraub M, Revel-Vilk S (2013) Topical curcumin for the prevention of oral mucositis in pediatric patients: case series. Altern Ther Health Med 19:21-24

95. Carl W, Emrich LS (1991) Management of oral mucositis during local radiation and systemic chemotherapy: a study of 98 patients. J Prosthet Dent 66:361-369

96. Sahebjamee M, Mansourian A, Hajimirzamohammad M, Zadeh MT, Bekhradi R, Kazemian A, Manifar S, Ashnagar S, Doroudgar K (2015) Comparative efficacy of Aloe vera and benzydamine mouthwashes on radiation-induced oral mucositis: a triple-blind, randomised. Controlled Clinical Trial Oral Health Prev Dent 13:309-315

Publisher's note Springer Nature remains neutral with regard to jurisdictional claims in published maps and institutional affiliations.

\section{Affiliations}

Noam Yarom ${ }^{1,2}$ (D) Allan Hovan ${ }^{3} \cdot$ Paolo Bossi $^{4} \cdot$ Anura Ariyawardana $^{5,6} \cdot$ Siri Beier Jensen $^{7} \cdot$ Margherita Gobbo $^{8}$. Hanan Saca-Hazboun ${ }^{9} \cdot$ Abhishek Kandwal $^{10}$. Alessandra Majorana ${ }^{11}$ • Giulia Ottaviani ${ }^{8}$. Monica Pentenero ${ }^{12}$. Narmin Mohammed Nasr ${ }^{13}$. Tanya Rouleau ${ }^{14}$. Anna Skripnik Lucas ${ }^{15} \cdot$ Nathaniel Simon Treister ${ }^{16,17}$. Eyal Zur ${ }^{18}$. Vinisha Ranna ${ }^{19}$. Anusha Vaddi ${ }^{20,21} \cdot$ Andrei Barasch ${ }^{22} \cdot$ Rajesh V Lalla $^{21} \cdot$ Karis Kin Fong Cheng $^{23} \cdot$ Sharon Elad $^{20} \cdot$ On behalf of the Mucositis Study Group of the Multinational Association of Supportive Care in Cancer / International Society of Oral Oncology (MASCC/ISOO)

1 Oral Medicine Unit, Sheba Medical Center, Tel Hashomer, Israel

2 School of Dental Medicine, Tel Aviv University, Tel Aviv, Israel

3 British Columbia Cancer-Vancouver Centre, Vancouver, Canada

4 Department of Medical and Surgical Specialties, Radiological Sciences and Public Health - Medical Oncology, University of Brescia, Spedali Civili, Brescia, Italy

5 College of Medicine and Dentistry, James Cook University, Cairns, QLD, Australia

6 Metro South Oral Health, Queensland Health, Brisbane, Australia

7 Department of Dentistry and Oral Health, Faculty of Health, Aarhus University, Aarhus, Denmark

8 Division of Oral Medicine and Pathology, Department of Medical, Surgical and Health Sciences, University of Trieste, Trieste, Italy

9 Al-Maha Cancer Foundation, Bethlehem, Palestine

10 Swami Rama Himayalan University Cancer research institute, Himalayan Institute of Medical Sciences, Dehradun, Uttarakhand, India

11 Dental School University of Brescia Radiological, Department of Medical and Surgical Specialties, Science and Public Health, Brescia, Italy

12 Department of Oncology, Oral Medicine and Oral Oncology Unit, University of Turin, Turin, Italy
13 Special Needs Dentistry, Dental Services, Ministry of Health, Muscat, Oman

14 Dental Oncology Program, Health Sciences North, North East Cancer Center, Sudbury, ON, Canada

15 Medical Oncology Service, Department of Medicine, NYU Langone Perlmutter Cancer Center, New York, NY, USA

16 Division of Oral Medicine and Dentistry, Brigham and Women's Hospital, Boston, MA, USA

17 Harvard School of Dental Medicine Department of Oral Medicine, Infection and Immunity, Boston, MA, USA

18 Compounding Solutions, Tel-Mond, Israel

19 The Mount Sinai Hospital Department of Oral and Maxillofacial Surgery New York 10029, NY, USA

20 University of Rochester Medical Center Oral Medicine, Eastman Institute for Oral Health Rochester, New York, USA

21 Division of Oral and Maxillofacial Diagnostic Sciences, UConn School of Dental Medicine, UConn Health, Farmington, CT, USA

22 Dental Clinics, Cambridge Health Alliance, Cambridge, MA, USA

23 National University of Singapore Alice Lee Centre for Nursing Studies, Yong Loo Lin School of Medicine, Singapore, Singapore 